\title{
Successful Surgical Management of Tumours in Rats
}

\author{
J. J. Parmar*, A. H. Parray, A. I. Shah, Neha Rao and D. J. Godasara \\ Veterinary Clinical Complex, College of Veterinary Science and Animal Husbandry, \\ Anand Agricultural University, Anand-188001, India \\ *Corresponding author
}

A B S T R A C T

\section{Ke y w o r ds \\ Surgical management, \\ Tumours, \\ Ultrasonographic examinations \\ Article Info \\ Accepted: \\ 17 August 2020 \\ Available Online: \\ 10 September 2020}

\section{Introduction}

Rats are genetically predisposed to a high incidence of tumours and mostly are benign tumours (Raja Ramesh, 2016). The most common tumours are mammary Fibroadenomas, occurring in $36.1 \%$ of females and $2.6 \%$ of males while dermal fibromas occurred in $4.5 \%$ of males and $3.0 \%$ of females (Poteracki and Walsh, 1998). The removal of tumor timely with careful surgical management is necessary to save the life of animals. This paper presents successful surgical management of fibroadenoma of mammary gland and fibroma in three female rats.

\section{History and clinical examinations}

Three white female rats age approximately one year weighing $300 \mathrm{gms}, 350 \mathrm{gms}$ and 650 gms, respectively, presented to Veterinary Clinical Complex, Veterinary College, Anand with history of gradually increased swelling on thoracic region on left side (Fig. 1, case 1) and right side (Fig. 2, case 2) while other rat had mass on right side of neck (Fig. 3, case 3 ). The clinical examinations of rats revealed rats were active, on palpation tumour masses were soft, round and posterior to armpit attached to mammary gland at left side and right side of thorax without any pain in case 1 and 2 while in small round mass on right side 
of neck in case 3. The ultrasonographic examination revealed $4.37 \mathrm{~cm}$ x $2.41 \mathrm{~cm}$ homogenous anechoic mass in case 1 (Fig. 4), $4.96 \mathrm{~cm} \times 3.01 \mathrm{~cm}$ homogenous hypoechoic mass in case 2 (Fig. 5) and homogenous hypoechoic mass (Fig. 6) in case 3 . On the bases of history, clinical and ultrasonograohic examination the cases were diagnosed as a tumour and surgical excision was planned.

\section{Treatment and Discussion}

In rat preanesthtic fasting is not required. The sites were prepared for aseptic surgery in all rats. Under general anaesthesia using Inj. Ketamine@75 mg/kg and Inj. Midazolam@ $5 \mathrm{mg} / \mathrm{kg}$ subcutaneously following standard surgical protocols and principles the rats were kept in lateral recumbancy as tumour mass remain upward site. The tumour masses were resected by blunt dissection. There was no much bleeding in case 1 and 2 while some higher amount of bleeding noted in case 3 which was control by ligation. The muscles and subcutaneous tissue sutured separately by continuous suture technique using Polyglactin 910 no. 2.0 and skin was apposed by interrupted suture pattern using Ethicon no. 2.0 in all rats. The resected tumour masses were weighing $90 \mathrm{gms}$ and $100 \mathrm{gms}$ in case 1 and 2, respectively and subjected to histopathological examination which revealed neoplastic proliferation of acinar epithelial cells and fibroblast confirms fibroedinoma of

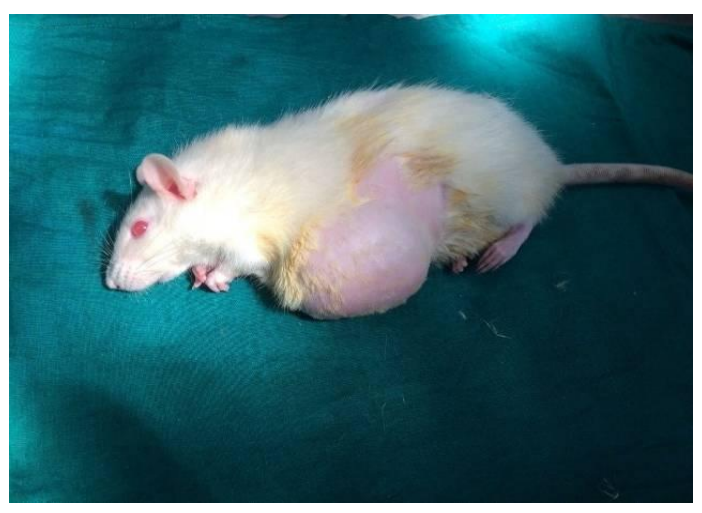

Fig.1 Mass on left side of thorax mammary gland (Fig. 7, case 1 and 2) and neoplastic proliferation of fibroblast in all directions under $\mathrm{H}$ \& $\mathrm{E}$ stain confirms fibroma (Fig. 8, case 3). Post-operative rats were advised to regular antiseptic dressing and oral Amoxicillin and Clavulanate @ 20 $\mathrm{mg} / \mathrm{kg}$ for five days. The stiches removed at twelve days of surgery. Commonly fibroadenoma are located in armpits, belly or groin areas (Madheswaran et al., 2014). In our cases location of tumor was at left and right side of thorax near armpit in case 1 and 2 treated with surgical excision. The ultrasonographic appearance found to be different in case 1 and 2 even tumor grossly and histopathologically similar type. Similar cases of fibroadenoma were reported by Shafiuzama et al., (2010) and Kathio and Tunio, (2016) where tumor located on ventral abdomen and left lateral thorax region, respectively, and surgical excision was performed. If benign tumor remain untreated than it continue to grow and become larger up to the half of the body weight. Factors like genetic, physiological and hormonal status and diet plays a role in occurrence of tumor. There are no references in same line while screening the literature towards surgical management for fibroma in rats. Prognosis is good after surgical removal of tumor masses in rats and its only choice of treatment. In this study both rats were recovered well without any complications.

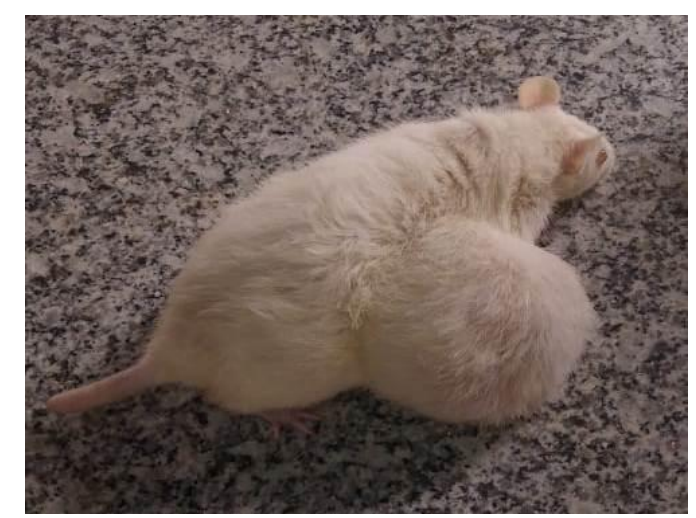

Fig.2 Mass on right side of thorax 


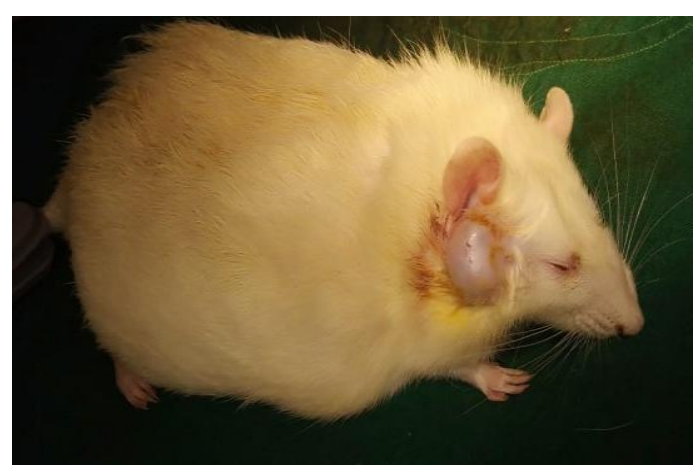

Fig.3 Mass on right side of neck

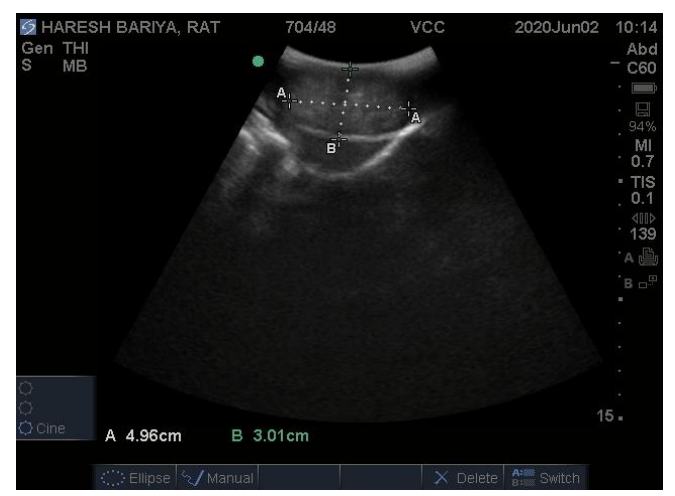

Fig.5 4.96 x $3.01 \mathrm{~cm}$ homogenous hypoechoic

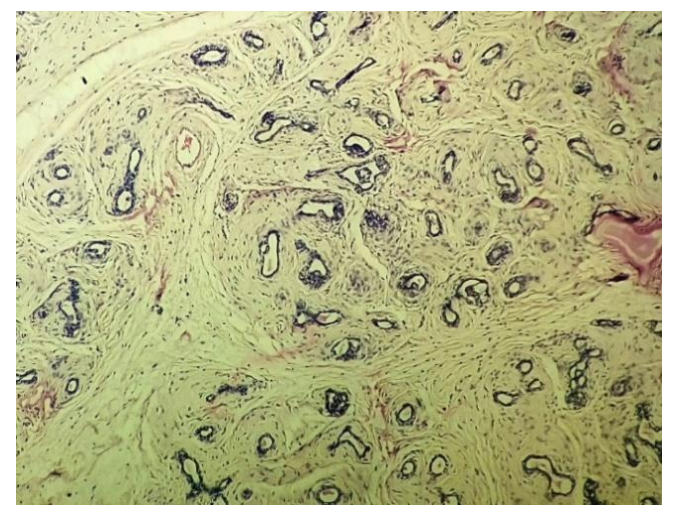

Fig.7 Fibroadenoma of mammary gland

\section{Acknowledgements}

Authors are grateful to the Dean of the College and University authorities of AAU, Anand for the facilities provided for this work.

\section{References}

Kathio, I. H. and Tunio, A. N. (2016).

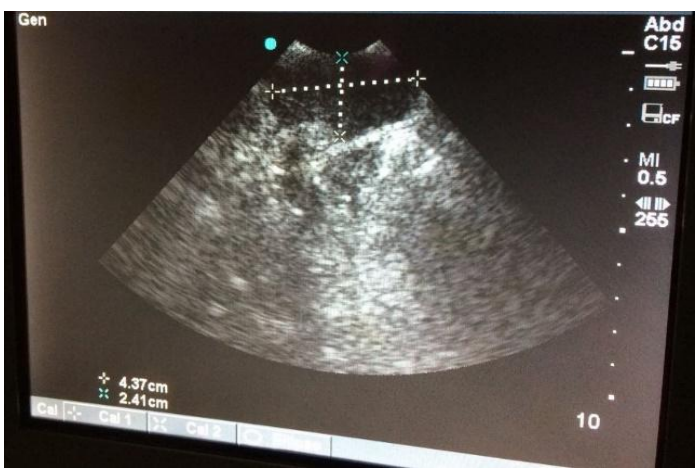

Fig.4 4.37 x $2.41 \mathrm{~cm}$ homogenous anechoic mass

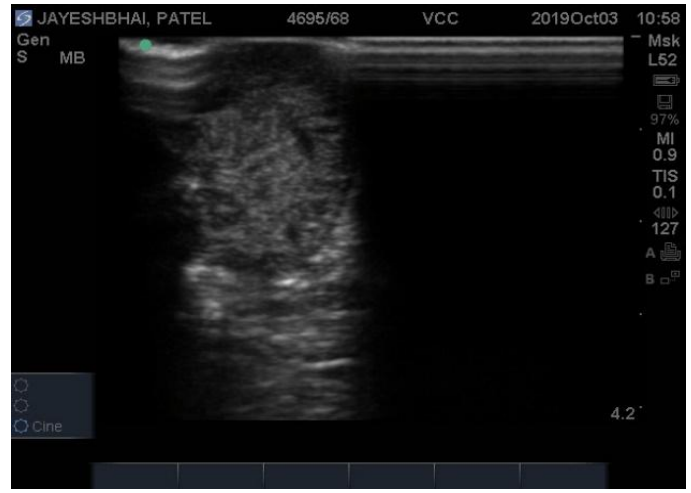

Fig.6 Homogenous hypoechoic mas

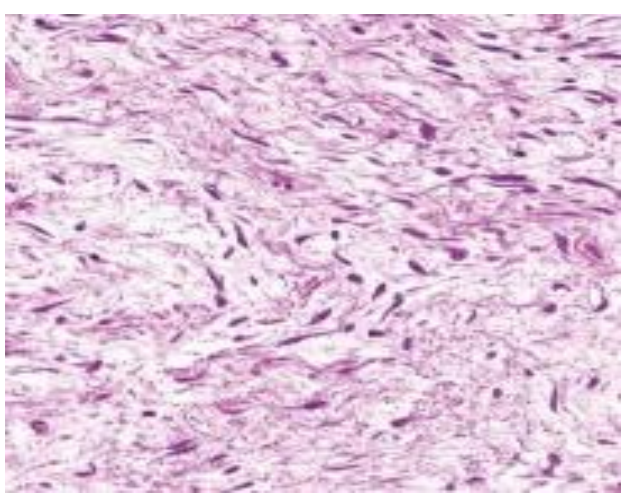

Fig.8 Fibroma

Surgical removal of a fibroadenoma in a domesticated rat (Rattus Norvegicus): Original case study. Pak. J. Agri. Engg. Vet. Sci. 32 (1):132-135.

Madheswaran, R., Srinivasan, M. R., Sivaseelan, S., Balasubramaniam, G. A., Arulmozhi, A. and Balachandran, P. (2014). Mammary adenocarcinoma in Wister rat- A case report. Indian J. Vet. Pathology 38(2): 128-130. 
Mohd. Shafiuzama, M., Simon, S., Das, B. C., Rao, G. D., Kannan, T. A. and Suresh Kumar, R. (2010). Mammary Fibroadenoma in a Rat and its surgical Management. Veterinary World, 3(5): 235.

Poteracki, J and Walsh, K. M. (1998).

Spontaneous Neoplasms in Control

Wistar Rats: A Comparison of Reviews.
Toxicological Sciences, 45: 1-8. Raja Ramesh, G. V. (2016). Types of Cancer and Surgery in Rats (Rattus norvegicus). Research \& Reviews: Journal of Veterinary Sciences, 3(1):49.

\section{How to cite this article:}

Parmar, J. J., A. H. Parray, A. I. Shah, Neha Rao and Godasara, D. J. 2020. Successful Surgical Management of Tumours in Rats. Int.J.Curr.Microbiol.App.Sci. 9(09): 2118-2121. doi: https://doi.org/10.20546/ijcmas.2020.909.264 